\title{
A Brazilian Pedagogic Project in Biological Sciences Teacher Development in a Problem Raising Perspective
}

\author{
M. O. J. M. Mathias ${ }^{1}$, H. Z. Fischer ${ }^{2}$, V. P. Almedia $^{3}$, S. G. Moraes ${ }^{4}$, N. C. Polimeno ${ }^{5}$ \\ ${ }^{1}$ Departamento de Tecnologia da Educação, Faculdade de Educação, Pontifícia Universidade \\ Católica de São Paulo, (PUC/SP) \\ ${ }^{2}$ Departamento de Ciências do Ambiente, Faculdade de Ciências Médicas e da Saúde, Pontifícia \\ Universidade Católica de São Paulo (PUC/SP) \\ ${ }^{3}$ Departamento de Morfologia e Patologia, Faculdade de Ciências Médicas e da Saúde, Pontifícia \\ Universidade Católica de São Paulo (PUC/SP) \\ ${ }^{4}$ Departamento de Morfologia e Patologia, Faculdade de Ciências Médicas e da Saúde, Pontifícia \\ Universidade Católica de São Paulo (PUC/SP) \\ ${ }^{5}$ Technical Advisor on Education
}

\begin{abstract}
Professional development requires from universities curricular innovations that promote the reorientation of the educational and development process, as well as integration of teaching, research and professional practice. Scientific knowledge is an invaluable tool that enables those involved in the educational process to understand and transform the reality in which they live, becoming actors of the improvement process of life quality, in a society with big social inequalities. The Institutional Pedagogical Project (IPP) by PUC/SP shows that the Pedagogical Project of the Course on Biological Sciences must be translated in new references that guide the pedagogical actions, in order to prepare professionals to cope with the demands of society nowadays. One of the ways to identify the demands is to let education take place in the real world, so that students and teachers experience the real social complexity, from which problems are raised. The IPP emphasizes the relevance of humanistic development as one of the main references. The needs of the working world can be regarded through the view of responsible citizenship, guided by the principles of cooperation and social justice, in a contextualized perspective, to build knowledge. The theoretical basis of problem raising education is used for the curricular reform of the Course on Biological Sciences, with the introduction of a structure in a model of a curricular matrix which can guarantee the articulation of a Common Nucleus which meets the needs of the development of both, Teachers and Bachelors.
\end{abstract}

\section{Introduction}

The proposal for curricular reform presented here is the product of a very complex process experienced by PUC/SP since 1994, mainly through Forums of Licenciature: a space for critical reflexive discussions aiming to create courses for Teacher Development based on the IPP and on the Institutional Project for Teacher Development in Elementary Education (IPTDEE), elaborated and approved by the Council of Teaching, Research and Extension (CTRE) and by the University Council - CONSUN.

Such Projects (IPP and IPTDEE) reflect the Brazilian national policy, proposed through official documents, aiming to reform teaching in all instances. Thus, these documents are referred to in the Brazilian Law for Education: "Lei de Diretrizes $e$ Bases da Educação, 9394/96".

The pedagogic project of the Course on Biological Sciences elaborated is in tune with the National Directions for this Course, which consider that: "the study of Biological Sciences must enable the understanding that life was organized a long time, under the action of the evolution processes, having resulted in a diversity of forms on which selective pressures keep on taking place. The organisms, including the human beings, are not isolated, on the contrary, constitute systems which establish complex relations of interdependence. The understanding of such interaction involves the understanding of the physical conditions of the environment, the way of life and the internal functional the organization, peculiar to the different species and biological systems. However, particular attention must be given to the relations 
established by the human beings, due to their specificity. In such approach, the biological knowledge is not dissociated from the social, political, economical and cultural knowledge"

The IPP emphasizes the humanistic development as one of its main references, made explicit in the institutional position: rather that neglecting the needs of the working world, they are regarded through the view of responsible citizenship, guided by the principles of cooperation and social justice, not by competition and individuality, in a contextualized perspective, not a technicist one, to build knowledge.

The IPP served as a reference for the reform of the Course on Biological Sciences for licenciates to teach, and $\mathrm{s}$ in the process of elaboration of the new curricular directions. In this way, the implementation of the new curriculum of the course defines innovative directions for the professional development of university level, incorporating new curricular designs towards more dynamic and integrative practices of the set of experiences that characterize the student's path of development. The number of hours covered in the Course on Biological Sciences for licenciates to teach follows the IPTDEE by PUC/SP.

Based on such guidelines, the Commission of Curricular Reform of the Course on Biological Sciences structured the Course in such a way that its functioning is qualified by a model of curricular matrix to guarantee the articulation of a Common Nucleus with Courses of the Faculty of Medical Sciences and Health of which it is part, for the development of both, Teachers an Bachelors.

Thus, the Pedagogical Project of the Course on Biological Sciences for licenciates to teach tries to reflect: the identity of the Course, with continuous exchange of experiences with the Course for Bachelors; development quality by PUC/SP configured by the practice of a model of teaching which uses research as a tool; and the guarantee that the teaching practice goes beyond the physical space of University, meeting the local and national expectations.

\section{Articulation of the course with research and extension}

The implementation of the Course on Biological Sciences in 1992, and the hiring of teachers with high ability to perform scientific research, promoted a process of reflection on the part of the professionals towards the improvement and integration of the learning activities together with research and extension. As a result, there was an increase in the number of researchers filed for scientific initiation, as well as in the development of actions of extension integrated to the research and learning activities. In addition, there are End of Course Projects in the field of Natural Sciences and
Biology.

Concerning the activities related to extension, the Faculty of Medical Sciences and Health has been developing different actions, such as "Operation Clean River", "Zoo therapy", participation in "ExpoGreen" and "Day of Sorocaba River", organized by the Council of Sorocaba, as well as Rondon Project at regional and national level.

Nowadays, besides all that, the teachers and students of the Course on Biological Sciences develop activities with the teachers and students of the Courses on Medicine and Nursing (PUC/SP), in an interdisciplinary action. The Program Health for the Family is the guide for the actions, together with the Municipal System of Health for the citizens of Sorocaba, Projects Pro-Health I and II, and a Project for Health called PET, besides action in Rondon Project.

\section{The Course in tune with the social - occupational transformations}

The licenciate in Biological Sciences has a wide range of possibilities for professional performance which has been expanding lately, as a result of expansion of knowledge presented in the different fields of Sciences, as well as in the fields of Education.

The curricular proposal is in tune with such transformation dynamics as it is concerned not only with the theoretical / practical development of the student, but also with the competencies and abilities to be developed to meet the present demand, open to detect the future ones which will emerge with the evolution of society.

\section{Articulation of the Course in the local, regional and national context}

The challenge to adjust the Pedagogical Project of the course, based in the best models of governmental Universities, required a diagnostic evaluation of the role of the teacher in society nowadays. Since the time the first course on Natural History was developed, many generations of Biologists and teachers have been graduated, performing in the field of education and research, brilliantly.

To improve the performance of the teacher of Natural Sciences and Biology, integration of actions to the environmental issues in the regional context, through new teaching approach has been considered. The student is encouraged to raise real problems related to Biological Sciences in the realm of the schools and the environment of the Faculty of Medical Sciences and Health. That is our challenge: develop teachers who are able to "learn how to learn" and perpetuate an attitude of acceptance of challenges.

Based on the principles of problem raising 
education, whose focus is in the students' learning, encouraged by the teacher through the creation of different situations that promote the understanding and construction of knowledge, the students take the responsibility for their own learning.

Emphasis is placed on the students, as well as in what and how they learn. This attitude fosters students who are active, creative, critical and responsible.

The practice of self learning since the first grade of the course makes students develop the ability to learn how to learn, as well as the perception of the need for permanent education to face the continuous and rapid changes of scientific knowledge.

The curricular pedagogical model, by establishing that learning is performed through the resolution of situations detected as problems in a student centred process, helps develop the information - oriented ability, selection and application in the resolution of the initial problem. Thus, we consider that the curricular matrix, organized through problem raising education considers the need to develop integral education, with emphasis in the following dimensions of development: specific and technical knowledge; pedagogical knowledge, interpersonal knowledge, relational knowledge, and human knowledge.

\section{Profile of the professional to be developed}

The Course on Biological Sciences aiming to develop teachers for the Elementary School and High School with solid knowledge of the basic contents related to Biological Sciences; who care for the dignity of their profession and for the quality of the school work under their responsibility; who constantly revise the ways of learning in face to expanded knowledge, avoiding "teaching as learnt before", and that make their pedagogical practice a source of reflection.

The teacher - researcher developed by PUC/SP is expected to be able to adjust the basic contents of Biological Sciences to the social reality, of the students or not, but in the case of students' reality, the educational practise takes into consideration the characteristics of the students and community in which the school in inserted, with constant development in class of critical reflection elaboration of autonomous thinking.

Besides, the teacher of the course is expected to be critical and active in relation to social issues, pertaining to the contents related to Biological Sciences or not.

He / she are expected to take part in a collective and cooperative way of the elaboration, development and evaluation of the curricular and educational project of the school, thus performing in different contexts of the professional practice, besides the class.

\section{Educational Approaches}

There are 4 educational approaches for problem raising education:

I. Problematization

II. Learning based on research or by projects

III. Learning based on problems

IV. Learning based on teams

\subsection{Problematization}

Problematization is an educational approach which enables education to take place in the real world, helping students and teachers experience and know the real social complexity involved, which is a demand of the present society referred to in the IPP. It starts with students' observation of real scenario, seeking to answer the question: "what is going on"? Observation of something complex like reality, with multiple contradictions, generates questionings and detection of various problems. According to Berbel the first stage - observation of reality is the moment when the problems are elaborated and contextualized by the group of students [2]. In the second stage - key-points, the students reflect and discuss from questions like: "Why does the problem exist?" What are some possible causes?

The understanding of the problems is a result of theorization and subsequent creation of hypotheses for the solution of one or all of them. Once chosen, the intervention selected will be applied to reality. The original problem is expected to be solved, bringing about transformation of the reality initially observed, through dialogue and negotiation among the different actors.

According to Berbel, in the third stage theorization, students seek for scientific knowledge, understand such knowledge and develop various abilities; in the fourth stage - hypothesis for the solution of the problem, some hypothesis are built during the studies performed by the students; the fifth stage - application to the reality of the project of intervention, there is acting in the specific reality, showing commitment on the part of the students with the reality observed, analysed and discussed [2]. These stages are represented in Figure 1.

Such educational approach aims to develop critical consciousness, not only guide understanding of the concepts and basic mechanisms of science. As society and education are related, the process of problematization offers a political dimension to education, making teachers and students aware of the rights and duties of the citizen, thus, having a strong emancipatory and liberating character. In this way, problematization shows to be very efficient and adequate for the work in the field, in the community.

By putting the student in contact with the social economical reality, mainly in the lower social classes, requiring for him/her an intervention to bring 
a solution to a particular situation, problematization shows to be a strategy able to make concrete the requirements by IPP, when it states: "PUC/SP by following the transformations of the contemporary society, particularly the processes that have been taking place in the Brazilian Society since the 90s, is aware of the need for redefinition that updates the University with the requirements of present time".

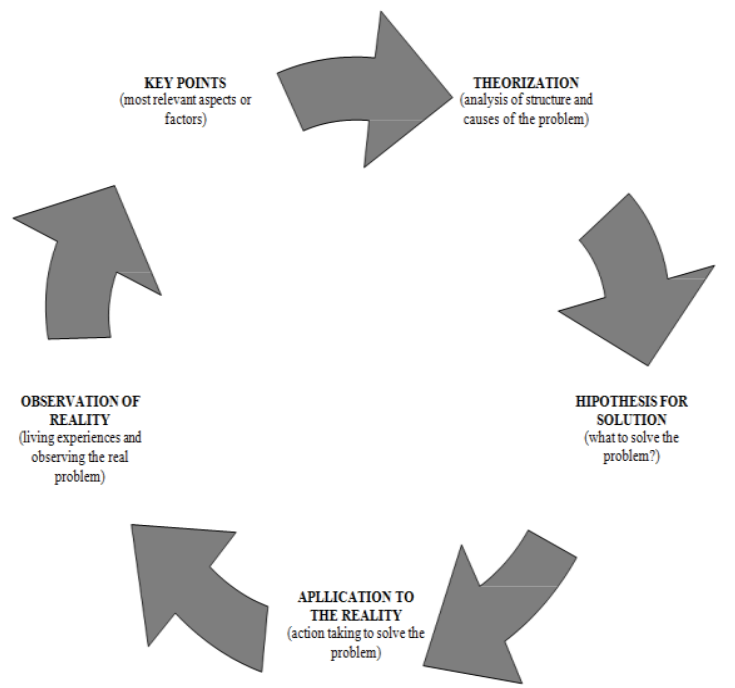

Figure 1. Problematization Stages

\subsubsection{Learning based on research or by projects}

The learning based on research or by projects (LBPr) helps students learn through own elaboration, replacing curiosity for listening with curiosity for producing.

Moved by his/her will and curiosity, the student raises temporary certainties and doubts, and can define a problem to be investigated through the use of judgement criteria based on relevance, in relation to a particular context.

Finally, the student is expected to create and develop the planning of a project in a cooperative way.

As the Scientific research methodologies are used, they are better incorporated, knowledge and abilities related to various fields are developed, together, with the ability to write and present scientific work.

This educational approach is in tune with the IPP when it proposes: "the new paradigms show the need for a pedagogic process that, effectively, makes concrete the indissociability among teaching research-extension".

\subsubsection{Problem based learning}

Problem based learning (PBL) started at the
McMaster de Hamilton University in Ontario, Canada in the mid 60s, where it was devised as a "guiding philosophy" for the development of a new medical school. It was introduced as a new method of education, in which learning is student centred, under the principal of adult learning, that is, self directed and encouraging the development of abilities to learn along life. These central elements were identified as critical for the preparation of doctors in an emerging era in which there was consciousness of a patient/consumer, concerning health and disease.

The model from McMaster has become a reference for the development of others. For example, the Case Western Reserve University incorporated similar methods of instruction in a laboratory for learning that served as a scenario for many disciplines.

Since the late 60s, many other universities like Maastricht in Holland and Newcastle in Australia adopted such approach to improve medical education. In North America, even very well known centres for their excellence started developing their own educational conception, based on these new

principles. That happened from Harvard to Boston, from Missouri to Hawaii, from Pittsburgh to Texas, as well as from Sweden to South Africa.

In Brazil, the first institutions to adopt the PBL for medical education were the Faculty of Medicine of Marilia in 1997, and the Faculty of Medical Sciences from the State University of Londrina, in 1998.

In PBL, the students work on a problem, extracted and elaborated on an everyday situation, thus providing content for meaningful learning. The problem challenges and motivates the students to understand it. Discussions in small groups (tutorial sessions) constitute the opportunity to use previous knowledge, at the same time that require new information, creating semantic nets.

In this scenario, learning takes place in a cooperative way, minimizing competition and making students able to work in group through a constructive interpersonal relationship. The analysis of the problem follows a sequence similar to the methodology of scientific research, in which research is regarded as "a processual attitude of investigation in face of the unknown", rather than an isolated act. Understood in this way, research is part of all practice, part of the information process, as an essential tool for liberation. As an educational principle, research is a basic process of emancipatory education, besides enabling students to solve complex problems in the future.

After the initial tutorial, students seek for answers to questions they themselves raised, and so, will be able to validate, or not, the hypothesis of explanation devised by the group. As people have different ways of learning, the self guided study allows each one to choose the most efficient way to do it, having the opportunity to practice for 
continuous education.

In the second meeting, the problem is discussed again with the new information brought by the members of the group, occasion in which a new cognitive elaboration takes place. The students bring information from different sources, with variable degrees of complexity.

While this learning is shared and explained to the others students, arguments are raised for their conceptions. Such practices guarantee articulated and substantial understanding of the context which will be long lasting in the memory.

PBL is based on tutorial sessions. The students are divided in groups of 10. Each group is conducted by a tutor, (teacher, not necessarily an expert in the subject).

The role of the tutor is not to answer students' doubts, but to instigate them to study and seek for further information in books, magazines and school material by the Faculty (laboratory, library, herbarium, museum and others.) Students are alsoencouraged to seek for help with consultant professors. Thus, the tutor is a facilitator and mediator between the students and knowledge.

In the dynamics of a tutorial, there must be, besides a tutor or facilitator, a secretary and a coordinator chosen among the students of the group in each session, in turn, so that all the students can experience this position.

Technically, the cycle of activities of the tutorial is called "steps of PSL" [3]. The process starts with the reading of the problem, previously elaborated as a result of collective construction by the teachers involved, toward the teaching / learning objectives for that module. The steps for a tutorial session are the following:

\subsection{Clear understanding of terminology and expressions used in the definition of the problem}

In order to make sure the problem is clearly stated and understood, students discuss in group, the terminology and expressions used, explaining them in the following session.

\subsection{Definition of the Problem}

After a group discussion (coordinated by the student elected by their students of the group, under the supervision of the tutor) questions are defined, as the object of analysis. The student in the position of a secretary (elected just like the coordinator) writes them on the board, to be easily visualized by everybody.

\subsection{Analysis of the problem (brainstorming)}

Discussions are performed around the questions defined, seeking for explanations based on previous knowledge that students have.

\subsection{Systematization of the explanations with the hypotheses proposed}

In the sequence, students propose, in the scientific format, some possible justifications to explain the questions previously raised and / or the problem as a whole.

\subsection{Learning objectives}

The students make a proposal of which learning objectives may validate the hypotheses raised, that is, what is it that must be learned to enable to understanding of the problem and the questions defined.

\subsection{Devising an action plan}

The group of students, with the help of the tutor, is expected to systematize the necessary actions to meet the learning objectives, like visit laboratory and other places, access books and magazines, contact consultant teachers, and any other actions that seem necessary.

\subsection{Self learning}

Individually, in between tutorial sessions, students are expected to study unknown terminology of the text to meet the learning objectives and any other subjects to complete the analysis of the problem, thus, actively seeking for answers to the questions defined. That can be accomplished through learning material and / or with the help of consultant teachers, previously indicated, who are experts in some aspects involved in the solution of the problem and may help find the answers to the questions. The consultants have to be prepared not to solve the problems for the students, but encourage them to extend knowledge beyond that case.

\subsection{Closing the problem}

After their studies in the following session, the students meet again under the supervision of the tutor. In this second tutorial meeting, the students individually present the results of the study. Based on the ideas systematized in the previous session, the solution of the problem proposed will emerge. The conclusion will take place with the construction of a flowchart, summarizing the elements involved in the problem, taking it to the final solution, with the knowledge required. At the end of the session, another problem may be open to restart the process. Each tutorial session is finalized with a formative evaluation, in which each student 
verbally evaluates the own performance, as well as the order members' of the group and the tutor's, who in return, evaluates the group and him/her self. Everyone evaluates the quality of the problem whose discussion was finalized in the session.

The strategy of PBL meets the requirements of the IPP, which emphasize: "previous experiences should be recognized and welcome, as well as the rhythm, unique way of each student to acquire knowledge; stimulating collective creation and the processes inherent in it."

In PBL, the role of the teacher stops being that of information transmission, but rather becomes the one who develops, which is in tune with what is stated in the IPP: "Take into consideration the formative and informative dimensions in the process of teaching / learning based on the insertion of the student in a social class, genre, religion, expressions of social, cultural, ideological values and ethnical - racial relations".

PBL must be understood as a strategy of curricular construction, rather than a mere educational method, as for its adequate application, it requires space for self learning and other educational actions of support.

As PBL enables to change the curricular design, it allows the other forms of problem raising education to be used, too.

\subsubsection{Team based learning}

Team Based Learning (TBL) is based on the interaction in small groups, with the aim to expose and improve students' abilities to apply the content of the course [5].

There are 4 essential elements in TBL. When they are implemented, the scenario becomes appropriate for the learning of the teams of students, as well as for their progress.

\section{1 - Teams}

Teams must be formed and guided properly.

\section{2 - Responsibility}

Students must be responsible for the quality of their work, both individual and in teams.

\section{3 - Feedback}

Students should receive feedback frequently in the right time.

\section{4 - Project of Tasks and activities}

The homework and team work should promote learning and development of the teams.

\begin{tabular}{|c|c|c|c|c|c|}
\hline \multirow[t]{2}{*}{$\begin{array}{c}\text { Preparation } \\
\text { (Pre-Class) }\end{array}$} & \multicolumn{4}{|c|}{$\begin{array}{l}\text { Leaming Diagnostic } \\
\text { Diagnosis/Feedback }\end{array}$} & $\begin{array}{l}\text { Application } \\
\text { of the } \\
\text { Concepts } \\
\text { of the } \\
\text { Course }\end{array}$ \\
\hline & \multicolumn{4}{|c|}{45 to $7 ;^{\prime}$} & 1 to 4 hours \\
\hline 1 & 2 & 3 & 4 & 5 & 6 \\
\hline $\begin{array}{l}\text { Individual } \\
\text { Study }\end{array}$ & $\begin{array}{l}\text { Individual } \\
\text { Test }\end{array}$ & $\begin{array}{c}\text { Test } \\
\text { in } \\
\text { Teams }\end{array}$ & Applications & Applications & $\begin{array}{l}\text { Application } \\
\text { Activities }\end{array}$ \\
\hline
\end{tabular}

Figure 2. Sequence of Instructional Activities Based on teams

\subsection{Teams}

TBL requires from the teacher, supervision to form the teams, in such a way to deal with 3 important variables.

I. To assure that the teams have enough resources to accomplish the tasks, and that the resources are, approximately, of the same level for all the teams.

II. To avoid coalitions between the members who are likely to interfere with the development of the team, in terms of cohesion.

III. To assure that the teams have the opportunity to develop as learning teams.

Teacher's supervision in the formation of the teams is important as, for the benefit of different perspectives, the teams should be composed of different human resources (previous experience, sex and ethnic background).

\subsection{Responsibility}

The methodology of TBL requires the students to be responsible in face of the teacher and other members, concerning the quality and quantity of their individual work. Besides, the teams are expected to be responsible for the quality and quantity of the work as a whole.

\subsection{Feedback}

Students should receive immediate and frequent feedback, as it is the leverage in TBL; it is essential for the acquisition of the content of learning and has a huge impact in the development of the teams.

\subsection{Project of tasks and activities}

The project of tasks and activities constitutes a key-point to assure the students really need the interaction in teams. Priority should be given to the use of concepts from the course, for decision making, involving different complex themes. 


\section{Organization of the Curriculum as a Nucleus}

The Pedagogic Project for the Graduation Course on Biological Sciences as a Licentiate consists of 2802 hours and is organized in two Nuclei: The Common Nucleus (1692 hours) which is connected to the Bachelor's Degree and the Nucleus for Teacher Development (510 hours) which contains the Compulsory Curriculum Training (400 hours) and the Complementary Activities (200 hours), as shown in Figure 3:

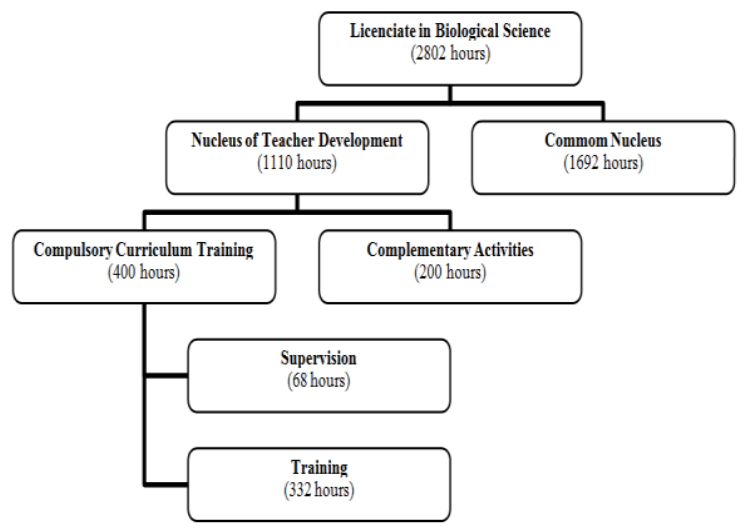

Figure 3. Organization of the Curriculum as a Nucleus

Table 1. Distribution of Activities of the Course on Biological Science / Licenciate - per term

\begin{tabular}{|c|c|c|c|c|c|}
\hline $\begin{array}{c}\text { Telm } \\
\text { (17 weeks) }\end{array}$ & $\begin{array}{l}\text { Teacher Developinent } \\
\text { (5 hours a day) }\end{array}$ & $\begin{array}{c}\text { Final course } \\
\text { project tutoring }\end{array}$ & $\begin{array}{c}\text { Training } \\
\text { Supervision }\end{array}$ & $\begin{array}{l}\text { Training } \\
\text { in loce }\end{array}$ & $\begin{array}{c}\text { Complementary } \\
\text { Activities }\end{array}$ \\
\hline $1^{\circ}$ & ModuleI (85 hours) & & & & \multirow[t]{6}{*}{200 hours } \\
\hline $2^{\circ}$ & Module II ( 85 hours) & & & & \\
\hline $3^{\circ}$ & Module III e IV (85 hours) & & & & \\
\hline $4^{\circ}$ & Module V e VI (85 hours) & & 17 hours & \multirow[t]{3}{*}{332 hours } & \\
\hline $5^{\circ}$ & Module VII (51 hours) & 34 hours & 17 hours & & \\
\hline $6^{\circ}$ & Module VIII (51 hours) & 34 hours & 34 hours & & \\
\hline Sub Total & 442 hours & 68 hours & 68 hours & 332 hours & 200 hours \\
\hline Total & \multicolumn{5}{|c|}{ 1110hour s } \\
\hline
\end{tabular}

\section{Nucleus of Teacher Development and its organization}

The Nucleus of Teacher Development consists of 1110 hours, to be developed in 6 terms. It is a fundamental and exclusive component for the Licentiate on Biological Sciences. 200 hours of Complementary Activities and 400 hours of Compulsory Curricular Training are part of this Nucleus (see Table 1).

\section{Teacher Development}

Module I: Principles on Education: Theoretical Conceptions
Module II: Challenges and Problems of the Brazilian Education

Module III: Education and Culture Module IV: Inclusive Education

Module V: LIBRAS - language for deaf and dumb people

Module VI: Educational Public Policies in Health

Module VII: Knowledge, Te a cher Planning and Practice

Module VIII: Pedagogic Project, Management and Public Policies

\section{Conclusion}

The Problem Raising Education allows students to be in contact with the social economic reality, particularly the part of society which is more in need, enabling intervention to solve the problem. It is configurated as a strategy that makes concrete the requirements of the IPP, concerning the need to redefine the role of the University to meet the needs of present times.

In the context of demands and challenges of society, there is the need of action taking in the field of Biological Sciences to contribute to the reversal of the processes of environmental degradation and improvement of the life quality of human population. These processes are mostly a result of not controlled economical cycles, growth without planning and recurring recession crisis, which affect agriculture,

industry and services, both in the urban and rural zones.

In the Brazilian society, we find chaotic expansion of economical activities, inserted in a system of production and consumption, based on extraction and maximal exploitation of natural resources to produce consumption goods. It is imperative to revert such state of affairs to a system of sustainable development, based on a kind of planning which respects the limits of the natural systems, biological and cultural diversity, committed with quality in the production of goods and services and international sharing of work, without, forgetting autonomy and interdependence of the nations.

Thus, it is vital to improve the process of information transmission, so that both production and consumption preserve the environment, once all living beings' health and quality of life depend on it. Quality of life for human beings should be understood as a sentry of the environment quality, not limited to a humanistic view, but holistic and ecological, which, therefore, involves knowledge from Biological, hard and human sciences.

University teaching, through teaching, research 
and extension makes it feasible for university students to get professional development considering the future, as a path of opportunities. The role of Education should gain new meaning, not being considered a compulsory step in a citizen's life, but rather a continuous way of improvement for personal and professional life.

University, as an education institution which produces science, is in a cross road between traditional education and progresses education. The former has valued memorization of contents to be reproduced; the latter follows the changes in science, culture and society. In such a scenario, professional development requires from university pedagogical innovations based on the advances of science teaching, for the construction of a new relation between education and society.

Such development is a "path connecting education and society", in which scientific knowledge is a tool enabling those involved in the educational process to improve life quality, in a society with huge social inequalities.

According to Zabalza, the university should make feasible the integration between teaching and research, and be a locus of: creation, development, transmission and criticism of science, knowhow and culture; preparation for professional performance that requires the use of knowledge and scientific methods, or for artistical creation; scientific and technical support for cultural, social and economic development, both at national level and in the autonomous communities, diffusion of the University culture [9].

Thus, we understand that the rapid changes from the end of XX century, force educators to revisit old themes in new contexts, new situations acquiring similar meanings.

The role of education nowadays is to foster the development of an educated society, instructed by means of accumulated knowledge, committed with the social and political dimensions; a kind of education for the citizens, involving all of them. The post modern society makes knowledge a privileged instrument for the understanding of reality. It is the society of knowledge, of learning.

The report of the International Commission for UNESCO on Education for the XXI century presented as one of the needs of society for this century and the future education along life, based on4 pillars: learning to interact, learning to know, learning to do, and learning to be.

This imposes to education more challenges that require reflection and suggest changes, besides encouraging innovation in the development and education process in institutions of graduation. As an example of such challenges, we can consider the development of professionals, educators - competent, creative and critical teachers, who can work in team at the same time that they perform with autonomy.
Thus, we can understand teacher development as a field of permanent study, in a society under transformation in all the dimensions.

According to Masetto the word innovation has been in fashion lately; it has countless meanings encompassing different things, at different levels of depth when used by the universities [4].

We have presented a proposal of a curricular innovation for the Course on Biological Sciences, taking in consideration the following presuppositions: the history of the Course on Biological Sciences / licenciating teachers from the Faculty of Medicine and Health / Campus Sorocaba; the political context for the IPTDEE; the analysis of the context of reality in which the Course is inserted; the concept of education we believe in; and the need for professional development of the teacher of Natural Science and Biology, in the present and future.

\section{References}

[1] U. F. Araujo and G. Sastre (orgs.). Aprendizagem baseada em problemas no ensino superior. São Paulo: Summus, Editorial, 2009.

[2] N. A. N. Berbel. A problematização e aprendizagem baseada em problemas: diferentes termos ou diferentes caminhos? In: Interface - Comunicação, Saúde, Educação. Botucatu: Fundação UNI / UNESP, p. 139 - 154, v.2, n.2. 1998.

[3] S. Mamede and J. Penaforte (orgs.) Aprendizagem baseada em problemas: anatomia de uma nova abordagem educacional. Fortaleza: Hucitec, 2001.

[4] M. Masetto (org.) Inovação no ensino superior. São Paulo: Edições Loyola, 2012.

[5] L. K. Michaelsen and M. Sweet. The essential elements of team-based Learning. New Directions for Teaching and Learning, 116, 7-27. 2008

[6] L. K. Michaelsen, A. B. Knight and L. D. Fink (Eds.). Team-based learning: A transformative use of small groups in college teaching. Sterling, VA: Stylus Publishing. 2004.

[7] V. M. Placco. Perspectivas e dimensões da formação e do trabalho do professor. In: Educação formal e não formal, saberes pedagógicos: desafios para a inclusão social. Recife - Pernambuco: Edições Bagaço: p. 251-262. 2006.

[8] W. Projeto Institucional de Formação de Professores da Educação Básica (PIFPEB). Pontifícia Universidade Católica de São Paulo. s/d. Projeto Pedagógico Institucional (PPI). Pontifícia Universidade Católica de São Paulo. 2004

[9] M. A. Zabalza. O ensino universitário: seu cenário e seus protagonistas. trad. Ernani Rosa. Porto Alegre: Artmed, 2004. 